\title{
Effects of a Nutritional Formulation Containing Caprylic and Capric Acid, Phosphatidylserine, and Docosahexaenoic Acid in Streptozotocin-Lesioned Rats
}

\author{
Eric L.R. Moura ${ }^{\mathrm{a}}$, Hellin dos Santos ${ }^{\mathrm{b}, *}$, Ana Paula M. Celes ${ }^{\mathrm{b}}$, Taysa B. Bassani ${ }^{\mathrm{a}}$, \\ Leonardo C. Souza ${ }^{\mathrm{a}}$ and Maria A.B.F. Vital ${ }^{\mathrm{a}}$ \\ ${ }^{a}$ Department of Pharmacology, Federal University of Paraná, Curitiba, PR, Brazil \\ ${ }^{\mathrm{b}}$ Scientific Department, Prodiet Medical Nutrition, Curitiba, PR, Brazil
}

Accepted 23 July 2020

\begin{abstract}
.
Background: It has been studied that nutrition can influence Alzheimer's disease (AD) onset and progression. Some studies on rodents using intraventricular streptozotocin (STZ) injection showed that this toxin changes cerebral glucose metabolism and insulin signaling pathways.

Objective: The aim of the present study was to evaluate whether a nutritional formulation could reduce cognitive impairment in STZ-induced animals.

Methods: The rats were randomly divided into two groups: sham and STZ. The STZ group received a single bilateral STZ-ICV injection $(1 \mathrm{mg} / \mathrm{kg})$. The sham group received a bilateral ICV injection of $0.9 \%$ saline solution. The animals were treated with AZ1 formulation (Instanth ${ }^{\circledR}$ NEO, Prodiet Medical Nutrition) $(1 \mathrm{~g} / \mathrm{kg}, \mathrm{PO})$ or its vehicle (saline solution) for 30 days, once a day starting one day after the stereotaxic surgery $(n=6-10)$. The rats were evaluated using the open field test to evaluate locomotor activity at day 27 after surgery. Cognitive performance was evaluated at day 28 using the object recognition test and the spatial version of the Y-maze test. At day 30 , the rats were anesthetized with chloral hydrate $(400 \mathrm{mg} / \mathrm{kg}$, i.p) and euthanized in order to evaluate IBA1 in the hippocampus. The differences were analyzed using one-way ANOVA with Bonferroni's or Kruskal Wallis with Dunn's post-hoc test.

Results/Conclusion: STZ-lesioned rats present memory impairment besides the increased microglial activation. The treatment with AZ1 formulation reversed the memory impairment observed in the object recognition test and Y-maze and also reduced IBA1 in CA1 and DG.
\end{abstract}

Keywords: Alzheimer’s disease, IBA1, Instanth ${ }^{\circledR}$ NEO, object recognition test, streptozotocin, Y maze

\section{INTRODUCTION}

Alzheimer's disease (AD) is a neurodegenerative disease and the most common form of dementia.

*Correspondence to: Hellin dos Santos, Rua General Potiguara, 1428, 81050-500 Curitiba, Parana, Brazil. Tel.: +5541 3616 6487; E-mail: hsantos@prodiet.com.br.
It is mainly characterized by progressive and slow memory loss, especially sporadic memory (related to recent events) and spatial disorientation. AD presents common histopathological findings, evidenced by protein accumulations. These findings are described as intracellular neurofibrillary tangles in cortex and hippocampal neurons caused by tau protein hyperphosphorylation, and as amyloid- $\beta$ extracellular 
filamentous aggregation, also called senile plaques [1-7]. Disease progression also causes hippocampal, neocortex, and amygdala atrophy, mainly seen in postmortem examinations. Such protein dysfunctions also result in a cascade of events involving neuronal loss, neuroinflammation, glial reactivity, cognitive and functional disorders [1-6], and decreased cerebral glucose metabolic rate, which worsens the cognitive status [8-13].

Many of the signals seen in AD, such as severe cognitive impairment, neuroinflammation, and oxidative stress, are also described after intracerebroventricular (ICV) injection of streptozotocin (STZ), being validated by several studies [14-18]. This toxin, produced by the bacterial strain Streptomyces achromogenes, is commonly used for animal models of type II diabetes for its ability to act on $\beta$-pancreatic cells and cause insulin resistance. However, STZ can cause cerebral glucose metabolic rate dysfunction by inhibiting insulin receptors when administered ICV at sub-diabetogenic doses. These factors trigger neuroinflammation, glial activation, and neuronal death, as well as a cognitive decline related to loss of spatial and recognition memory, very similarly to AD symptoms [15-18].

$\mathrm{AD}$ also presents abnormal complications of neuronal membrane lipids with increased cholesterol to the detriment of phosphatidylserine [19-21]. In this context, oral phosphatidylserine supplementation can cross the blood-brain barrier and increase the brain supply of this nutrient [21]. Some experimental studies showed that phosphatidylserine helped improve cognitive problems and performance on tasks testing short-term learning and memory skills [21].

Another important nutrient in the composition of the neuronal membrane is docosahexaenoic acid (DHA), which has a complementary function to phosphatidylserine supplementation. About 20-30\% of phosphatidylserine in gray matter is combined with DHA [22, 23]. Decreased phosphatidylserine DHA in cerebral cortex is associated with AD mild cognitive impairment progression [21, 24]. In addition, the brain is vulnerable to lipid peroxidation, decreasing membrane fluidity, damaging membrane proteins, and resulting in membrane breakdown [25]. In the STZ-induced AD model, Pardeshi et al. [26] demonstrated that DHA improved the efficacy of the pharmacological agent used in the study and increased survival and neuronal memory, decreasing oxidative stress and inflammation.

Diets that induce ketone body formation have been related to preserved cognition and reduced tau protein and amyloid- $\beta$ pathology in $\mathrm{AD}$ animal models $[27,28]$. One of the mechanisms responsible for the formation of ketone bodies is the use of caprylic and capric fatty acids [29-31], even when added to regular meals, as they are rapidly absorbed by the portal system and beta-oxidized in the liver, generating excess acetyl-coA, which forms ketone bodies $[31,32]$. Ketone bodies cross the blood-brain barrier [33], enter the neurons, and produce ATP in the mitochondria by oxidative phosphorylation [31]. Thus, caprylic and capric acids are also important nutrients in $\mathrm{AD}$.

Although many nutrients seem to be important for brain health in AD, there are no studies evaluating these nutrients combined. The objective of the present study was to evaluate whether a formulation with a unique combination of capric acid, caprylic acid, phosphatidylserine, DHA, vitamins, and minerals can reduce cognitive impairment in STZ-induced animals as well as the neuroinflammatory markers of the model.

\section{MATERIALS AND METHODS}

\section{Animals}

This study included 32 young adult (approximately 3 months old) Wistar male rats (Rattus norvegicus) from the Central Laboratory Animal Facility of the Federal University of Paraná (UFPR) weighing 290-320 g at the beginning of the experiment.

Each five animals were kept in a polypropylene box with ad libitum water and food intake in a room with controlled humidity and temperature $\left(22 \pm 2^{\circ} \mathrm{C}\right)$ and $12 \mathrm{~h}$ light-dark cycle (7 a.m.-7 p.m.). The procedures were approved by the Animal Ethics Committee (CEUA) of the UFPR under protocol number 1226.

\section{Stereotaxic surgery}

The animals were deeply anesthetized with sodium thiopental $(30 \mathrm{mg} / \mathrm{kg}$, i.p.) and chloral hydrate $(150 \mathrm{mg} / \mathrm{kg}$, i.p.) followed by atropine sulfate $(0.4 \mathrm{mg} / \mathrm{kg} \mathrm{IP})$ as an anesthetic adjunct to reduce mucus production. The rats were placed in the stereotaxic equipment (David Kopf, 957L model) and positioned according to the following coordinates: anteroposterior (AP): $-0.8 \mathrm{~mm}$ from the bregma; mediolateral (ML): $\pm 1.5 \mathrm{~mm}$ from the midline; and dorsoventral (DV): $-3.8 \mathrm{~mm}$ from the skullcap [34]. The head region was shaved and a small skin incision 
Table 1

Composition per $100 \mathrm{~g}$ of the nutritional formulation AZ1

\begin{tabular}{lc}
\hline AZ1 Composition & $100 \mathrm{~g}$ \\
\hline Caprylic acid & $36 \mathrm{~g}$ \\
Capric acid & $27 \mathrm{~g}$ \\
DHA & $327 \mathrm{mg}$ \\
Phosphatidylserine & $546 \mathrm{mg}$ \\
Minerals & \\
$\quad$ Magnesium & $233 \mathrm{mg}$ \\
Zinc & $5.6 \mathrm{mg}$ \\
Selenium & $102 \mathrm{mcg}$ \\
Vitamins & \\
Vitamin D & $75 \mathrm{mcg}$ \\
Vitamin E & $56 \mathrm{mg} \alpha \mathrm{TE}$ \\
Vitamin C & $436 \mathrm{mg}$ \\
Vitamin B6 & $36 \mathrm{mg}$ \\
Folic Acid & $526 \mathrm{mcg}$ \\
Vitamin B12 & $12 \mathrm{mcg}$ \\
Niacin & $31 \mathrm{mg} \mathrm{NE}$ \\
Choline & $835 \mathrm{mg}$ \\
\hline
\end{tabular}

mas made to expose the skull. Subsequently, two incisions were drilled in the skull with a dental surgical drill, followed by the insertion of a 30-gauge needle connected to a polyethylene tube adapted to a $10 \mu \mathrm{L}$ micro syringe (Hamilton, USA) and connected to an infusion pump (Harvard Apparatus, USA).

The lesioned group received bilateral ICV injections of STZ (1 mg/kg total dose) dissolved in sterile saline ( $2 \mu l$ per injection site) into the lateral ventricles. The sham group animals underwent the same surgical procedure; however, they received only the diluent $(0.9 \%$ sterile saline solution) instead of the STZ solution.

Microinfusion was programmed at a rate of $1 \mu \mathrm{L} / \mathrm{min}$ for $2 \mathrm{~min}$. The needle remained at the infusion site for $2 \mathrm{~min}$ after the end of the procedure to avoid reflux, and then the skin incision was sutured. After that, the animals received $1 \mathrm{~mL}$ of saturated sodium bicarbonate solution IP to accelerate anesthetic elimination and $0.1 \mathrm{~mL}$ of penicillin $\mathrm{G}$ procaine $2.000 \mathrm{IU} / \mathrm{mL} \mathrm{IM}$ to prevent possible infections.

At the end of the surgery, the rats were placed back in warmed boxes until complete recovery.

\section{Drugs}

Streptozotocin (STZ, Santa Cruz Biotechnology, Santa Cruz, CA, USA) $1 \mathrm{mg} / \mathrm{kg}$ and AZ1 formulation (Instanth ${ }^{\circledR}$ NEO, Prodiet Medical Nutrition, PR, Brazil). AZ1 formulation was administered by gavage $(1 \mathrm{~g} / \mathrm{kg})$ once a day for 30 days and its composition is in Table 1.

\section{Experimental design}

The animals were randomly divided into four experimental groups: STZ + saline $(n=6)$, $\mathrm{STZ}+\mathrm{AZ} 1$ formulation $1 \mathrm{~g} / \mathrm{kg}(n=9)$, sham + saline $(n=10)$, and sham $+\mathrm{AZ} 1$ formulation $1 \mathrm{~g} / \mathrm{kg}(n=7)$. Animals in STZ groups received a bilateral $2 \mu \mathrm{L}$ microinfusion of STZ solution $(1 \mathrm{mg} / \mathrm{kg})$ dissolved in sterile saline solution. Animals in sham groups underwent the same surgical procedure; however, they received the same amount of $0.9 \%$ sterile saline solution instead of the STZ solution. The groups were treated with AZ1 formulation $(1 \mathrm{~g} / \mathrm{kg}$ ) or saline solution for 30 days, once a day in the afternoon, starting one day after surgery.

At day 27 after surgery the animals underwent the open field test (OFT) to evaluate spontaneous locomotion and rearing frequency. At day 28 the animals underwent the object recognition (ORT) and the Y-maze tests, which evaluated spatial memory and short-term recognition. Finally, at day 30 the animals were deeply anesthetized with hydrated chloral $(400 \mathrm{mg} / \mathrm{kg}$, IP) and euthanized with an intracardiac perfusion process. Subsequently, the brain structures were prepared and immunohistochemically evaluated with the expression of the microglia-specific marker for ionized calcium-binding adaptor molecule (IBA1).

\section{Open field test}

The OFT is a behavioral test widely used to measure locomotor and behavioral characteristics in rodents. It is an easy-to-perform test based on physiological concepts well discussed in the literature that is also used to evaluate anxiety and exploratory behavior [35-37].

The test takes place in a white round arena $(97 \times 42 \mathrm{~cm})$ divided by three concentric circles into three parts subdivided by straight segments into 19 quadrants with a central circle where the animal was carefully placed, allowing it to freely explore the entire area for $5 \mathrm{~min}$. This study analyzed two motor parameters: locomotion (ambulation) and rearing frequency. Locomotion is one of the most analyzed factors [36] and considers the quadrants the animal crosses with all four paws as a measure of motor activity [35]. Rearing is the frequency with which the animal stands on its hind legs and measures exploratory activity [35]. The arena was cleaned prior to each animal test with $20 \%$ water-ethanol solution to eliminate odors and substances left by the previous rat. 


\section{Object recognition test}

The ORT is associated to the ability the animal has to distinguish between known and new objects. Rodents have an intrinsic tendency to spend more time exploring new than familiar objects [38]. This decreased novelty may be related to repeated exposure to a new stimulus that eventually becomes familiar; however, it should not be confused with decreased exploratory interest [38].

The ORT takes place in a square black (to avoid clues) box $(100 \times 100 \times 40 \mathrm{~cm})$ made of wood and positioned in a moderate light environment (20 lux). A camera was positioned above the box for subsequent image analysis in order to avoid interference due to the presence of the handler in the test environment. The test started with an adaptation session in which the animals were placed in the box for $5 \mathrm{~min}$ for free exploration of the environment. Another $5 \mathrm{~min}$ session was held $24 \mathrm{~h}$ later and the test started $1 \mathrm{~h}$ after [39]. Session one was a training session. The animals were placed in the test box with two identical objects and had $5 \mathrm{~min}$ to explore them before being placed back in the habitat box. One hour after the initial exposure, the animals were placed back in the test box with a new object for 3 min. This session was recorded for later evaluation of how much time the animal spent interacting with each object [40].

The objects used in the test were made of plastic or ceramic and cleaned with $20 \%$ ethanol (standardized by the laboratory) after each session to avoid the influence of the smell of other animals [40]. The objects were randomly arranged to reduce the bias of preference for specific place or object. Weights have been added to objects so that the rat could not move or knock them down [17, 41]. All animals were placed in the box facing the same wall in both sessions [39]. A chronometer was used to measure the time the animal explored the objects, which was considered only when the animal smelled an object at a distance less than $2 \mathrm{~cm}$ or touched the object with the muzzle. Sitting, rearing, or walking around objects were not considered exploratory behaviors [42].

Exploratory behavior was measured by counting how much time the animal explored each object during the test session [40]. The time spent by the animal exploring the familiar object and the new object will be represented by ' $a$ ' and 'b', respectively. The variable ' $e$ ' is the sum of the total exploration time of the new and familiar objects during the test session. The variable ' $d$ ' is an index of discrimination between the new and the familiar objects and was considered a relative measure to correct the exploratory activity of the animal. Thus, the formula was: $\mathrm{e}=\mathrm{a}+\mathrm{b}$; and $\mathrm{d}=(\mathrm{b}-\mathrm{a}) / \mathrm{e}$ [39].

\section{Spatial version of the Y-maze test}

In this test the animal was placed in a Y-shaped maze with three identical arms at an angle of $120^{\circ}$. These arms measured $50 \times 12 \times 27 \mathrm{~cm}$. The maze was placed in a controlled light room (20 lux). A camera was positioned above the maze for subsequent image analysis in order to avoid interference due to the presence of the handler in the test environment.

The test consisted of two steps with a $1 \mathrm{~h}$ interval between them: a training and a test session. In the training session, the animals were randomly placed in one arm of the maze but a removable wood door previously positioned restricted the access to one of the other arms. At this stage the animals could freely explore two arms of the maze for $5 \mathrm{~min}$ and after were placed back in the habitat box. The test session took place $1 \mathrm{~h}$ after. The animals were placed in the same arm where they started the training session but the barrier that prevented the animal from accessing one arm was previously removed, allowing free exploration of all arms for $3 \mathrm{~min}$. This session was recorded and the parameter evaluated was the time the animal stayed in the unknown arm. The maze was cleaned with $20 \%$ ethanol between sessions to avoid the influence of the smell of other animals on the test $[17,41,43]$.

The time each animal stayed in the unknown arm was corrected by latency to leave the initial arm and time spent in the center of the maze. Animal entrance in one of the arms was considered when it had all paws inside the arm [17, 41, 43].

\section{IBA1 immunohistochemistry}

Brain sample processing and immunohistochemistry reactions were developed as described by Bassani et al. [17]. The animals were deeply anesthetized and then euthanized with an intracardiac perfusion of saline phosphate buffered solution (pH $7.4 ; 1,000 \mathrm{~mL} / \mathrm{kg} ; 4^{\circ} \mathrm{C}$ ), followed by $4 \%$ paraformaldehyde in phosphate buffered solution $\left(\mathrm{pH} 7.4 ; 1,000 \mathrm{~mL} / \mathrm{kg}, 4^{\circ} \mathrm{C}\right)$. Then the brains were removed and placed in 30\% sucrose solution for 4 days for tissue cryoprotection. After that, the tissue was protected with plastic, quickly frozen in liquid nitrogen and stored in a freezer $\left(-80^{\circ} \mathrm{C}\right)$ for subsequent sectioning [17]. The frozen tissue was cut into 
$30 \mu \mathrm{m}$ semi-serial coronal sections along the dorsal hippocampus at a temperature of $-25^{\circ} \mathrm{C}$ using a cryostat (Leica Biosystems, Nusslock, Germany). The dorsal hippocampus was collected and the sections were placed serially in ten well-plates using -2.56 to $-4.52 \mathrm{~mm}$ stereotaxic coordinates in relation to the bregma [34], totaling six to eight $300 \mu \mathrm{m}$ cuts per well-plate. Brain sections were stored at $-20^{\circ} \mathrm{C}$ in cryoprotectant solution containing $30 \%$ ethylene glycol and $15 \%$ sucrose in $0.05 \mathrm{M}$ phosphate buffered solution for subsequent processing $[17,41]$.

The free-floating method was used for immunohistochemical reactions with the IBA1 marker. The brain sections were initially washed with buffer A $(0.1 \mathrm{M}$ PBS, pH 7.4 with $0.5 \%$ Triton X-100) and incubated in $0.1 \mathrm{M}$ citrate buffer, $\mathrm{pH} 6.0$ in a water bath at $50^{\circ} \mathrm{C}$ for $30 \mathrm{~min}$. The steps described above characterize an antigen retrieval step for this marker. After that, the sections were cooled to room temperature, washed with buffer $\mathrm{A}$, incubated with $0.5 \% \mathrm{H}_{2} \mathrm{O}_{2}$ solution in $0.1 \mathrm{M}$ PBS for $30 \mathrm{~min}$ at room temperature and protected from light, washed again with buffer A and incubated with $2 \%$ bovine serum albumin (BSA) in buffer A (blocking buffer) at room temperature for $1 \mathrm{~h}$. Subsequently, the plates containing the sections were incubated overnight at $4^{\circ} \mathrm{C}$ with the primary antibody diluted in anti-IBA1 goat polyclonal blocking buffer $(1: 500$, Abcam, Cambridge, MA, USA) $[17,41]$.

The following day the sections were washed in buffer A and incubated with biotinylated secondary antibody at $4{ }^{\circ} \mathrm{C}$ for $2 \mathrm{~h}$, washed again in buffer $\mathrm{A}$ and incubated with $\mathrm{ABC}$ reagent (Vectastain Elite $\mathrm{ABC}$ Kit, Vector Laboratories, Burlingame, CA, USA) in $0.1 \mathrm{M}$ PBS at room temperature for $2 \mathrm{~h}$. After being washed with $0.1 \mathrm{M}$ PBS, the reaction was revealed by incubating the sections with 3,3'-diaminobenzidine (DAB, Vector Laboratories, Burlingame, CA, USA) in $0.1 \mathrm{M} \mathrm{PBS}$ at room temperature. The sections were washed in $0.1 \mathrm{M}$ PBS, mounted on gelatinized slides and air dried $[17,41]$.

\section{Statistical analysis}

The data are presented as mean \pm standard error of the mean (SEM). The data were tested for a Gaussian distribution using the KolmogorovSmirnov test. Group differences were analyzed using one-way analysis of variance (ANOVA) with Bonferroni's post-hoc test for parametric data or Kruskal Wallis (IBA-1 analysis in the CA1 region of the

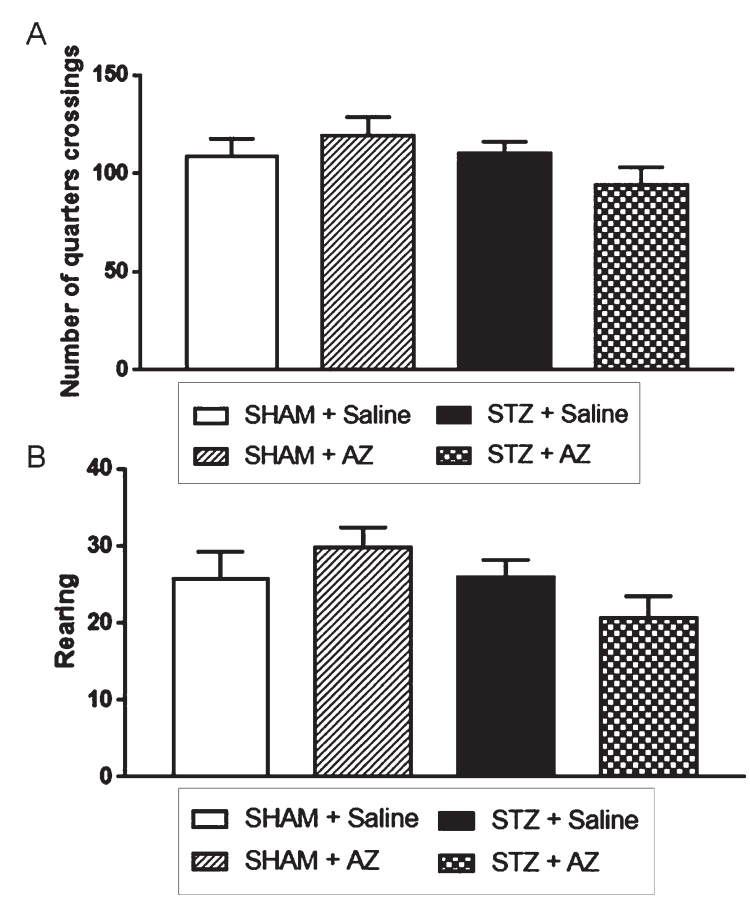

Fig. 1. Effects of $A Z 1$ formulation on noncognitive performance of STZ-ICV-injected animals $(1 \mathrm{mg} / \mathrm{kg})$. Noncognitive performance was evaluated using the open field test. The parameters analyzed were spontaneous locomotor activity (A) and exploratory behavior (B). The data are shown as mean \pm SEM; $n=6-10$ per group. (One-way ANOVA with Bonferroni's post-hoc test).

Hippocampus) with Dunn's post-hoc test for nonparametric data. Values of $p<0.05$ were considered statistically significant.

\section{RESULTS}

\section{Open field test}

The analysis of number of quadrants traveled by the animals (Fig. 1A) at day 27 after surgery showed no significant motor activity differences between groups. Thus, there were also no changes regarding motor capacity between groups. In addition, the OFT allowed the analysis of rearing behavior (Fig. 1B), when the animals stood on both hind legs. This analysis showed no significant exploratory capacity differences between groups, so all animals in this study had similar exploratory activities.

\section{AZ1 formulation effects on animal cognition}

Animal recognition memory was evaluated using the ORT (Fig. 2A) at day 28. The execution 

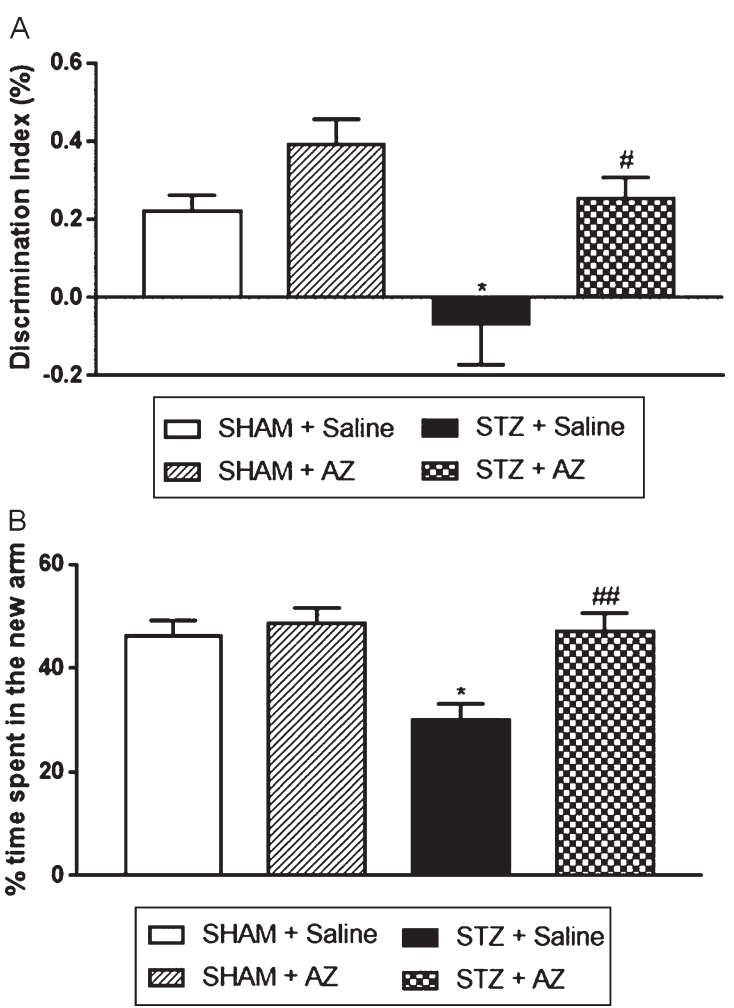

Fig. 2. Effects of $A Z 1$ formulation on cognitive performance of STZ-ICV-injected animals. Cognitive performance was evaluated using the object recognition (A) and the spatial version of $\mathrm{Y}$ maze (B) tests. The data are shown as mean \pm SEM; $n=6-10$ per group; ${ }^{*} p<0.05$ versus sham group; ${ }^{\#} p<0.05$; ${ }^{\#} p<0.01$ versus STZ group (one-way ANOVA with Bonferroni's post-hoc test).

protocol requires a $1 \mathrm{~h}$ interval between training and test sessions.

Animals in the STZ + saline group showed a statistically significant decrease in the discrimination index compared to the sham + saline group, showing that STZ-lesioned animals were unable to discriminate new and familiar objects. Animals in the $\mathrm{STZ}+\mathrm{AZ1}$ group showed a statistically significant increase in the discrimination index compared to the STZ + saline group, showing that AZ1 formulation was able to revert the memory loss caused by STZ. In addition, short-term spatial memory evaluated by spatial version of the Y-maze test (Fig. 2B) showed that the rats in the STZ + saline group spent a significantly decreased percentage of time exploring the new arm compared to the sham + saline group. The AZ1 formulation treatment significantly reversed cognitive impairment in STZ-lesioned rats in the $\mathrm{STZ}+\mathrm{AZ1}$ group.
AZ1 formulation effects on neuroinflammation

IBA1 immunoreactivity (Fig. 3) was used as a parameter to analyze the influence of AZ1 formulation treatment on glial reactivity and neuroinflammation. Our data showed increased IBA1 immunoreactivity in the three analyzed hippocampal regions (CA1, CA3, and DG - dentate gyrus) in the STZ + saline group compared to the sham + saline group (Fig. 4). Immunoreactivity to IBA1 reduction in $\mathrm{CA} 1$ and DG regions (Fig. 3A-C) showed that AZ1 formulation treatment significantly reduced glial activation in STZ-lesioned animals; however, it did not change the marking in the CA3 region (Fig. 3B) compared to sham + saline animals. The groups sham + saline and sham + AZ1 formulation showed no significant differences in IR to IBA1 in any hippocampal region.

\section{DISCUSSION}

Prolonged AZ1 formulation treatment reversed cognitive impairment in both the ORT and the Y-maze test and reduced neuroinflammation in CA1 and DG hippocampal regions in STZ-lesioned rats.

This neuroprotective effect of AZ1 formulation may be due to the combination of several lipids, such as caprylic and capric acid, which produce ketone bodies and are a source of brain energy, and the combination of DHA and phosphatidylserine, which restructure neuronal membranes and have an antiinflammatory action. In addition, the presence of choline, acting on plasma phospholipid synthesis and structuring of cell membranes, vitamins and minerals which are extremely important for brain health.

An increased inflammatory process is associated with increased activation of microglia cells and astrocytes and progressive cognitive decline in humans $[44,45]$. Postmortem studies in humans showed CA1 and CA3 hippocampal regions presenting decreased neuronal density in AD patients [46]. Thus, the results of the present study corroborate the neuroinflammation reported in other studies [16, 17, 41].

Our results show that the STZ-lesioned animals that received only saline solution presented the shortterm object recognition and spatial memory deficits already mentioned in the literature, respectively by decreasing the discrimination index in the ORT [47, 48] and the time spent on the new arm in the Ymaze test [48]. In addition, STZ-related decreased spatial memory was already described in the Morris water maze test [49]. On the other hand, STZ-lesioned 
A
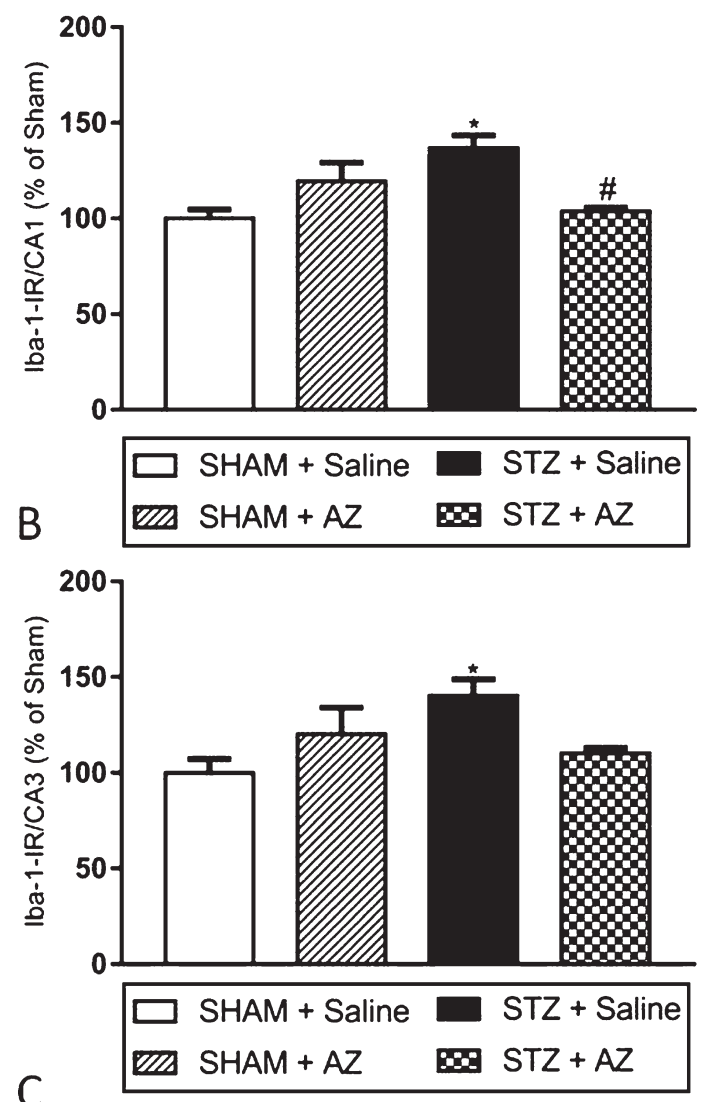

C

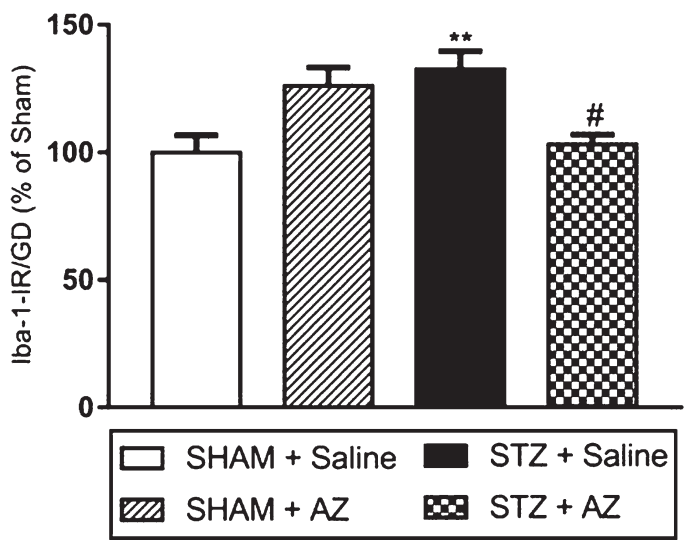

Fig. 3. Effects of AZ1 formulation on microglial cells (IBA1 immunoreactivity) on STZ-ICV-injected animals. IBA1-IR significantly increased in CA1 region 30 days after surgery in STZ-ICV-injected rats. The treatment with AZ1 formulation at a dose of $1 \mathrm{~g} / \mathrm{kg}$ reduced IBA-IR in hippocampal regions CA1 (A) and DG (C) but showed no significant results in CA3 region (B). The data are shown as mean $\pm \mathrm{SEM} ; n=4-6$ per group; ${ }^{*} p<0.05 ; * * p<0.01$ versus sham + saline group; ${ }^{\#} p<0.05$ versus $\mathrm{STZ}+$ saline group (one-way ANOVA with Bonferroni's post-hoc test on IBA1 immunoreactivity in the CA3 and GD regions, and Kruskal Wallis with Dunn's post-hoc test for the hippocampus CA1 region). animals treated with the enteral AZ1 formulation showed significant improvement in the evaluated parameters when compared to STZ+ saline animals, indicating that AZ1 formulation components reversed spatial and object recognition memory impairment.

Spontaneous locomotion and exploratory behavior are important in all test groups, since changes in these parameters could decrease the animal's performance in subsequent cognitive tests [17]. Performance comparison among the four experimental groups showed no significant noncognitive behavior differences, demonstrating that all animals had similar characteristics regarding exploratory capacity and locomotion.

Some experimental studies reported that phosphatidylserine increased interneuronal communication through increased cell membrane fluidity and attenuated acetylcholine reduction, in addition to improving performance on tasks that test short-term learning and memory skills [21]. In humans, phosphatidylserine increased glucose use and memory in information processing and ability to perform daily activities [50-56]. The incorporation of phosphatidylserine into human membranes depends on phosphatidylserine and DHA availability [21, 22].

The brain is vulnerable to lipid peroxidation, which decreases cell membrane fluidity and damages membrane proteins, contributing to membrane breakdown. Thus, in addition to the ideal combination with phosphatidylserine, DHA increases synapses and membrane fluidity, resulting in a more effective neurotransmitter function; besides inhibiting free radical production and reducing oxidative stress [25]. The use of omega-3 fatty acids has been reported in numerous AD animal models [57-60]. In the STZinduced AD model, Pardeshi et al. [26] showed that DHA improved the efficacy of the pharmacological agent used in the study by increasing survival and neuronal memory due to decreased oxidative stress and inflammation.

As for caprylic and capric acid and the consequent formation of ketone bodies, a clinical study reported better cognitive performance evaluated by logical memory and coding tests in individuals diagnosed with probable mild to moderate $\mathrm{AD}$ after ingesting $20 \mathrm{~g}$ of caprylic and capric acid. In addition, cognitive test scores were correlated with plasma ketone body levels [61].

Some antioxidant nutrients present in the AZ1 formulation, such as zinc, selenium, magnesium, vitamins $\mathrm{C}$ and $\mathrm{E}$, may be related to neuronal protection, since oxidative stress leads to DNA 


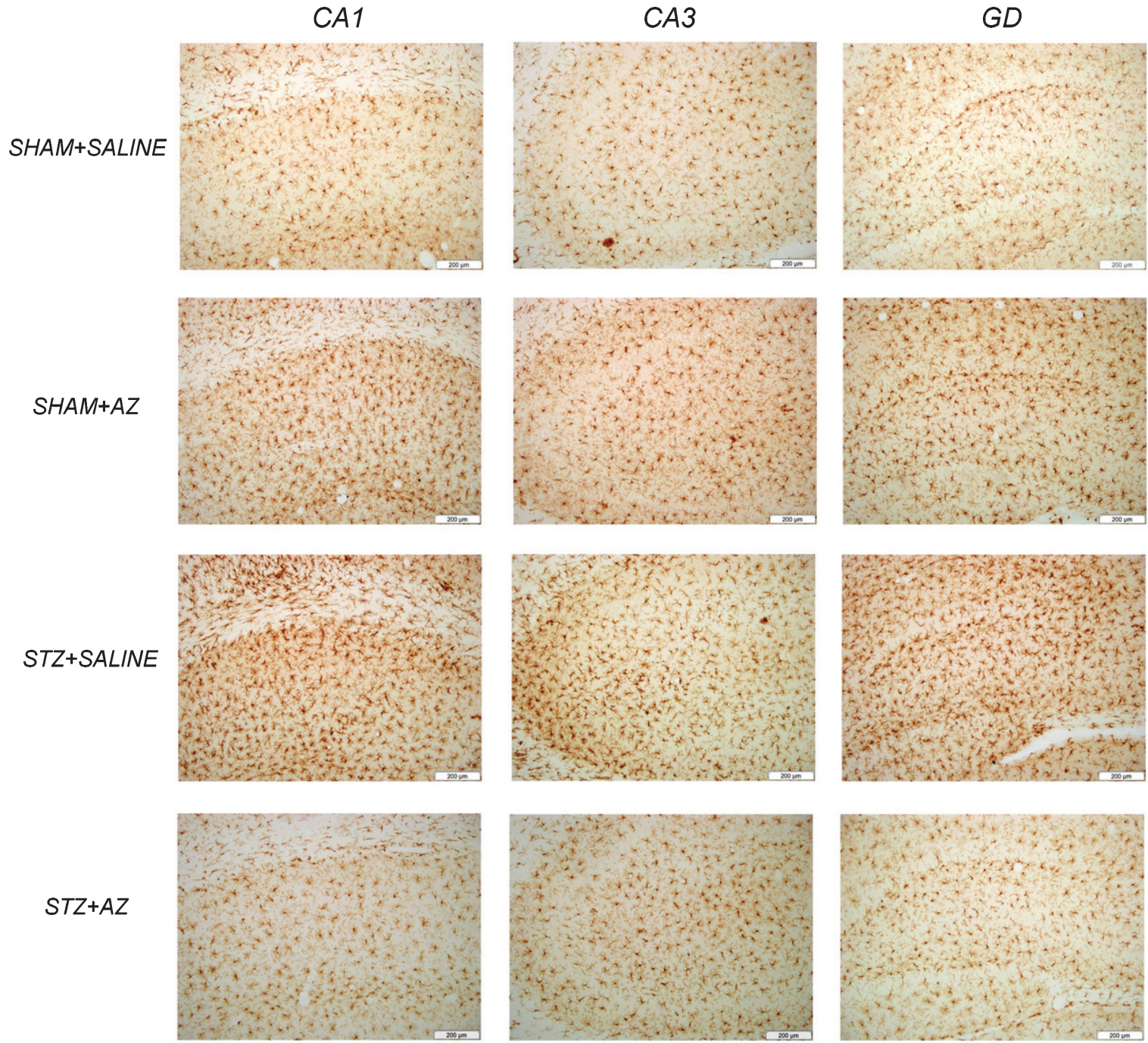

Fig. 4. Representative photomicrographs of IBA1-positive cells in CA1, CA3, and DG hippocampal regions. IBA1-positive cells in the hippocampal dentate gyrus (DG), CA1, and CA3 regions. Scale $=200 \mu \mathrm{m}$.

damage, which in turn leads to neuronal apoptosis and consequent neurodegeneration [62, 63]. In addition, AD-related decreased antioxidant levels can be observed in brain regions of elderly people [64]. Furthermore, vitamin D3 treatment improved spatial learning and functional memory in STZ-lesioned animals [65]. Vitamin D can prevent cognitive impairment and dementia through neuronal protection [66].

It should be highlighted that the ICV administration of STZ $(1 \mathrm{mg} / \mathrm{kg})$ was able to cause memory deficits that could be related to the earlier stages of AD. This combination of components used in the nutritional AZ1 formulation, which had never been tested together, was able to reverse STZ-induced memory impairment.
However, a possible limitation of this study is that we did not evaluate neither the amyloid- $\beta$ protein nor tau expression. According to Salkovic-Petrisic et al. [67], increased amyloid- $\beta$ deposition in the wall of meningeal capillaries and cortical blood vessels was found in icv-STZ rats. Results suggest that cerebral amyloid angiopathy observed 6 and 9 months after the STZ-icv injection seems to be a continuation and progression of the amyloid pathology observed already 3 months following the STZ-icv treatment in this non-transgenic sAD animal model. In this line, Ravelli et al. [68] showed that icv injections of STZ increase amyloid- $\beta$ expression in the hippocampus STZ and increased phosphorylation of tau in mice. 
In addition, according to Chen and collaborators [69], the deposition of amyloid- $\beta$ proteins in this model begin to be observed after 3 months of the ICV injection of STZ. In the present study, the evaluation of the prolonged administration of the AZ formulation was given to the subjects during 30 days. Maybe in our experimental design the deposition of tau and amyloid- $\beta$ proteins might not be sufficient to obtain conclusive results. Future studies, some of them now in progress, could help to answer these questions.

In conclusion, the present study showed that prolonged supplementation with AZ1 formulation reversed STZ-induced cognitive impairment in addition to decreasing the progression of neuroinflammation in CA1 and DG of the hippocampus.

\section{ACKNOWLEDGMENTS}

We thank Conselho Nacional de Desenvolvimento Científico e Tecnológico (CNPq) and Coordenação de Aperfeiçoamento de Pessoal de Ensino Superior (CAPES) for the financial support. MABF Vital is recipient of CNPq fellowship.

\section{CONFLICT OF INTEREST}

MABF Vital; TB Bassani and LC Souza declare no conflict of interest. ELR Moura was a collaborator on a grant supported by Prodiet.; H Santos is Scientific Specialist on Prodiet. APM Celes is Technical Director and Co-founder of Prodiet.

\section{REFERENCES}

[1] Ross CA, Poirier MA (2004) Protein aggregation and neurodegenerative disease. Nat Med 10, S10.

[2] Inouye K, Pedrazzani ES, Pavarini SCI, Toyoda CY (2009) Perceived quality of life of elderly patients with dementia and family caregivers: Evaluation and correlation. Rev Lat Am Enfermagem 17, 187-193.

[3] Cash DM, Ridgway GR, Liang Y, Ryan NS, Kinnunen KM, Yeatman T, Malone IB, Benzinger TLS, Jack CR, Thompson PM, Ghetti BF, Saykin AJ, Masters CL, Ringman JM, Salloway SP, Schofield PR, Sperling RA, Cairns NJ, Marcus DS, Xiong C, Bateman RJ, Morris JC, Rossor MN, Ourselin S, Fox NC (2013) The pattern of atrophy in familial alzheimer disease: Volumetric MRI results from the DIAN study. Neurology 81, 1425-1433.

[4] Haines JL (2018) Alzheimer disease: Perspectives from epidemiology and genetics. J Law Med Ethics 46, 694-698.

[5] Salardini A (2019) An overview of primary dementias as clinicopathological entities. Semin Neurol 39, 153-166.

[6] Calderon-Garcidueñas AL, Duyckaerts C (2017) Alzheimer disease. Handb Clin Neurol 145, 325-337.

[7] De Gregório E, Patrzyk LH, Bosetto Fiebrantz AK, Bonini JS, Cambruzzi DH, Diedrich C, Fermino BL, Fabbri R,
Nunes da Silva WCF (2019) Nutritional and hematological factors associated with the progression of Alzheimer's disease: A cohort study. Rev Assoc Med Bras 65, 222-231.

[8] de Leon MJ, Ferris SH, George AE, Christman DR, Fowler JS, Gentes C, Reisberg B, Gee B, Emmerich M, Yonekura Y, Brodie J, Kricheff II, Wolf AP (1983) Positron emission tomographic studies of aging and Alzheimer disease. Am J Neuroradiol 4, 568-571.

[9] Reiman EM, Chen K, Alexander GE, Caselli RJ, Bandy D, Osborne D, Saunders AM, Hardy J (2004) Functional brain abnormalities in young adults at genetic risk for lateonset Alzheimer's dementia. Proc Natl Acad Sci U S A 101, 284-289.

[10] Butterfield AD, Di Domenico F, Barone E (2015) Elevated risk of type 2 diabetes for development of Alzheimer disease: A key role for oxidative stress in brain. Biochim Biophys Acta 1842, 1693-1706.

[11] Weise CM, Chen K, Chen Y, Kuang X, Savage CR, Reiman EM (2018) Left lateralized cerebral glucose metabolism declines in amyloid- $\beta$ positive persons with mild cognitive impairment. Neuroimage Clin 20, 286-296.

[12] Croteau E, Castellano CA, Richard MA, Fortier M, Nugent S, Lepage M, Duchesne S, Whittingstall K, Turcotte ÉE, Bocti C, Fülöp T, Cunnane SC (2018) Ketogenic medium chain triglycerides increase brain energy metabolism in Alzheimer's disease. J Alzheimers Dis 64, 551-561.

[13] Arnold LM, Bennett RM, Crofford LJ, Dean LE, Clauw DJ, Goldenberg DL, Fitzcharles MA, Paiva ES, Staud R, Sarzi-Puttini P, Buskila D, Macfarlane GJ (2018) AAPT diagnostic criteria for fibromyalgia. J Pain 20, 611-628.

[14] Mayer G, Nitsch R, Hoyer S (1990) Effects of changes in peripheral and cerebral glucose metabolism on locomotor activity, learning and memory in adult male rats. Brain Res 532, 95-100.

[15] Duelli R, Schröck H, Kuschinsky W, Hoyer S (1994) Intracerebroventricular injection of streptozotocin induces discrete local changes in cerebral glucose utilization in rats. Int J Dev Neurosci 12, 737-743.

[16] Rostami F, Javan M, Moghimi A, Haddad-Mashadrizeh A, Fereidoni M (2017) Streptozotocin-induced hippocampal astrogliosis and insulin signaling malfunction as experimental scales for subclinical sporadic Alzheimer model. Life Sci 188, 172-185.

[17] Bassani TB, Turnes JM, Moura ELR, Bonato JM, CóppolaSegovia V, Zanata SM, Oliveira RMMW, Vital MABF (2017) Effects of curcumin on short-term spatial and recognition memory, adult neurogenesis and neuroinflammation in a streptozotocin-induced rat model of dementia of Alzheimer's type. Behav Brain Res 335, 41-54.

[18] Ravelli KG, Rosário B dos A, Camarini R, Hernandes MS, Britto LR (2017) Intracerebroventricular streptozotocin as a model of Alzheimer's disease: Neurochemical and behavioral characterization in mice. Neurotox Res 31, 327-333.

[19] Cenacchi T, Bertoldin T, Farina C, Fiori MG, Crepaldi G, Azzini CF, Girardello R, Bagozzi B, Garuti R, Vivaldi P, Belloni G, Bordin A, Durando M, Lo Storto M, Bertoni L, Battistoni A, Cacace C, Arduini P, Bonini A, Caramia MP, Vaglieri G, Brusomini A, Donà G, March A, Campi N, Cannas P, Casson F, Cavallarin G, Delia M, Cristianini G, Louvier O, Mello F, Fameli R, Urbani de Gheltoff N, De Candia O, Nante G, Cattoni C, Forte PL, Loreggian M, Targa A, Mansoldo G, Noro G, Meggio A, Pedrazzi F, Bonmartini F, Ruggiano C, Peruzza M, Olivari G, Recaldin E, Bellunato C, Rigo G, Marin M, Marinangeli L, Saracino A, Miceli O, Lovo G, Scarpa R, Battistello L, Tomat E, 
Bernava B, Olivo P, Verga G, Merli G, Zerman AM, Crivellaro R, Vozza A, Ziliotto GR, Favaretto V, Allegro L (1993) Cognitive decline in the elderly: A double- blind, placebocontrolled multicenter study on efficacy of phosphatidylserine administration. Aging Clin Exp Res 5, 123-133.

[20] Marra C, Silveri MC, Gainotti G (2000) Predictors of cognitive decline in the early stage of probable Alzheimer's disease. Dement Geriatr Cogn Disord 11, 212-218.

[21] Glade MJ, Smith K (2015) Phosphatidylserine and the human brain. Nutrition 31, 781-786.

[22] Kimura AK, Kim HY (2013) Phosphatidylserine synthase 2: High efficiency for synthesizing phosphatidylserine containing docosahexaenoic acid. J Lipid Res 54, 214-222.

[23] Tanaka K, Farooqui AA, Siddiqi NJ, Alhomida AS, Ong W (2012) Effects of Docosahexaenoic Acid on neurotransmission. Biomol Ther 20, 152-157.

[24] Cunnane S, Nugent S, Roy M, Courchesne-Loyer A, Croteau E, Tremblay S, Castellano A, Pifferi F, Bocti C, Paquet N, Begdouri H, Bentourkia M, Turcotte E, Allard M, Barberger-Gateau P, Fulop T, Rapoport SI (2011) Brain fuel metabolism, aging and Alzheimer's disease. Nutrition 27, 3-20.

[25] Parletta N, Milte CM, Meyer BJ (2013) Reviews: Current topics: Nutritional modulation of cognitive function and mental health. J Nutr Biochem 24, 725-743.

[26] Pardeshi R, Bolshette N, Gadhave K, Arfeen M, Ahmed S, Jamwal R, Hammock BD, Lahkar M, Goswami SK (2019) Docosahexaenoic acid increases the potency of soluble epoxide hydrolase inhibitor in alleviating streptozotocininduced Alzheimer's disease-like complications of diabetes. Front Pharmacol 10, 1-13.

[27] Van Der Auwera I, Wera S, Van Leuven F, Henderson ST (2005) A ketogenic diet reduces amyloid beta 40 and 42 in a mouse model of Alzheimer's disease. Nutr Metab 2, 1-8.

[28] Kashiwaya Y, Bergman C, Lee JH, Wan R, King MT, Mughal MR, Okun E, Clarke K, Mattson MP, Veech RL (2013) A ketone ester diet exhibits anxiolytic and cognitionsparing properties, and lessens amyloid and tau pathologies in a mouse model of Alzheimer's disease. Neurobiol Aging 34, 1530-1539.

[29] Seaton TB, Welle SL, Warenko MK, Campbell RG (1986) Thermic effect of medium-chain and long-chain triglycerides in man. Am J Clin Nutr 44, 630-634.

[30] Courchesne-Loyer A, Fortier M, Tremblay-Mercier J, Chouinard-Watkins R, Roy M, Nugent S, Castellano CA, Cunnane SC (2013) Stimulation of mild, sustained ketonemia by medium-chain triacylglycerols in healthy humans: Estimated potential contribution to brain energy metabolism. Nutrition 29, 635-640.

[31] Cunnane SC, Courchesne-Loyer A, Vandenberghe C, StPierre V, Fortier M, Hennebelle M, Croteau E, Bocti C, Fulop T, Castellano CA (2016) Can ketones help rescue brain fuel supply in later life? Implications for cognitive health during aging and the treatment of Alzheimer's disease. Front Mol Neurosci 9, 1-21.

[32] Schönfeld P, Wojtczak L (2016) Short- and medium-chain fatty acids in energy metabolism: The cellular perspective. J Lipid Res 57, 943-954.

[33] Simpson, IA; Carruthers, A; Vannucci S (2007) Supply and demand in cerebral energy metabolism: The role of nutrient transporters. J Cereb Blood Flow Metab 27, 1766-1791.

[34] Paxinos G, Watson C (1997) The rat brain in stereotaxic coordinates, 5th edition. Academic Press, San Diego.

[35] Walsh RN, Cummins RA (1976) The Open-Field Test: A critical review. Psychol Bull 83, 482-504.
[36] Seibenhener ML, Wooten MC (2015) Use of the open field maze to measure locomotor and anxiety-like behavior in mice. $J$ Vis Exp, e52434.

[37] Tatem KS, Quinn JL, Phadke A, Yu Q, Gordish-Dressman H, Nagaraju K (2014) Behavioral and locomotor measurements using an open field activity monitoring system for skeletal muscle diseases. J Vis Exp, 51785.

[38] Ennaceur A, Delacour J (1988) A new one-trial test for neurobiological studies of memory in rats. 1: Behavioral data. Behav Brain Res 31, 47-59.

[39] de Bruin NMWJ, Prickaerts J, van Loevezijn A, Venhorst J, de Groote L, Houba P, Reneerkens O, Akkerman S, Kruse CG (2011) Two novel 5-HT6 receptor antagonists ameliorate scopolamine-induced memory deficits in the object recognition and object location tasks in Wistar rats. Neurobiol Learn Mem 96, 392-402.

[40] Akkerman S, Prickaerts J, Steinbusch HWM, Blokland A (2012) Object recognition testing: Statistical considerations. Behav Brain Res 232, 317-322.

[41] Bassani TB, Bonato JM, Machado MMF, Cóppola-Segovia V, Moura ELR, Zanata SM, Oliveira RMMW, Vital MABF (2018) Decrease in adult neurogenesis and neuroinflammation are involved in spatial memory impairment in the streptozotocin-induced model of sporadic Alzheimer's disease in rats. Mol Neurobiol 55, 4280-4296.

[42] Mello-Carpes PB, Izquierdo I (2013) The nucleus of the solitary tract $\longrightarrow$ nucleus paragigantocellularis $\longrightarrow$ locus coeruleus $\longrightarrow$ CA1 region of dorsal hippocampus pathway is important for consolidation of object recognition memory. Neurobiol Learn Mem 100, 56-63.

[43] Sierksma ASR, Prickaerts J, Chouliaras L, Rostamian S, Delbroek L, Rutten BPF, Steinbusch HWM, van den Hove DLA (2013) Behavioral and neurobiological effects of prenatal stress exposure in male and female APPswe/PS1dE9 mice. Neurobiol Aging 34, 319-337.

[44] McGeer PL, Itagaki S, Tago H, McGeer EG (1987) Reactive microglia in patients with senile dementia of the Alzheimer type are positive for the histocompatibility glycoprotein HLA-DR. Neurosci Lett 79, 195-200.

[45] Janelidze S, Mattsson N, Stomrud E, Lindberg O, Palmqvist S, Zetterberg H, Blennow K, Hansson O (2018) CSF biomarkers of neuroinflammation and cerebrovascular dysfunction in early Alzheimer disease. Neurology 91, e867-e877.

[46] Padurariu M, Ciobica A, Mavroudis I, Fotiou D, Baloyannis S (2012) Hippocampal neuronal loss in the CA1 and CA3 areas of Alzheimer's disease patients. Psychiatr Danub 24, $152-158$.

[47] de Oliveira JS, Abdalla FH, Dornelles GL, Palma TV, Signor C, da Silva Bernardi J, Baldissarelli J, Lenz LS, de Oliveira VA, Chitolina Schetinger MR, Melchiors Morsch VM, Rubin MA, de Andrade CM (2019) Neuroprotective effects of berberine on recognition memory impairment, oxidative stress, and damage to the purinergic system in rats submitted to intracerebroventricular injection of streptozotocin. Psychopharmacology (Berl) 236, 641-655.

[48] Pacheco SM, Soares MSP, Gutierres JM, Gerzson MFB, Carvalho F, et al (2018) Anthocyanins as a potencial pharmacological agent to manage memory deficit, oxidative stress and alterations in ion pump activity induced by experimental sporadic dementia of Alzheimer's type. $J$ Nutr Biochem 56, 193-204.

[49] Ghahraman MA, Zahmatkesh M, Pourbakht A, Seifi B, Jalaie S, et al (2016) Noisy galvanic vestibular stimulation enhances spatial memory in cognitive impairment-induced 
by intracerebroventricular-streptozotocin administration. Physiol Behav 157, 217-224.

[50] Heiss WD, Szelies B, Kessler J, Herholz K (1991) Abnormalities of energy metabolism in Alzheimer's disease studied with PET. Ann N Y Acad Sci 640, 65-71.

[51] Heiss WD, Kessler J, Slansky I, Mielke R, Szelies B, Herholz K (1993) Activation PET as an instrument to determine therapeutic efficacy in Alzheimer's disease. Ann N Y Acad Sci 695, 327-331.

[52] Heiss WD, Kessler J, Mielke R, Szelies B, Herholz K (1994) Long-term effects of phosphatidylserine, pyritinol, and cognitive training in Alzheimer's disease: A neuropsychological, EEG, and PET investigation. Dement Geriatr Cogn Disord 5, 88-98.

[53] Delwaide PJ, Gyselynck-Mambourg AM, Hurlet A, Ylieff M (1986) Double-blind randomized controlled study of phosphatidylserine in senile demented patients. Acta Neurol Scand 73, 136-140.

[54] Crook T, Petrie W, Wells C, Massari DC (1992) Effects of phosphatidylserine in Alzheimer's disease. Psychopharmacol Bull 28, 61-66.

[55] Amaducci L (1988) Phosphatidylserine in the treatment of Alzheimer's disease: Results of a multicenter study. Psychopharmacol Bull 24, 130-4.

[56] Engel RR, Satzger W, Günther W, Kathmann N, Bove D, Gerke S, Münch U, Hippius H (1992) Double-blind crossover study of phosphatidylserine vs. placebo in patients with early dementia of the Alzheimer type. Eur Neuropsychopharmacol 2, 149-155.

[57] Calon F, Lim GP, Yang F, Morihara T, Teter B, Ubeda O, Rostaing P, Triller A, Salem N Jr, Ashe KH, Frautschy SA, Cole GM (2004) Docosahexaenoic acid protects from dendritic pathology in an Alzheimer's disease model. Neuron 43, 633-645.

[58] Lim GP, Calon F, Morihara T, Yang F, Teter B, Ubeda O, Salem N, Frautschy SA, Cole GM (2005) A diet enriched with the omega-3 fatty acid docosahexaenoic acid reduces amyloid burden in an aged Alzheimer mouse model. J Neurosci 25, 3032-3040.

[59] Kondo T, Asai M, Tsukita K, Kutoku Y, Ohsawa Y, Sunada Y, Imamura K, Egawa N, Yahata N, Okita K, Takahashi K, Asaka I, Aoi T, Watanabe A, Watanabe K, Kadoya C, Nakano R, Watanabe D, Maruyama K, Hori O, Hibino S, Choshi T, Nakahata T, Hioki H, Kaneko T, Naitoh M, Yoshikawa K, Yamawaki S, Suzuki S, Hata R, Ueno SI, Seki T, Kobayashi K, Toda T, Murakami K, Irie K, Klein WL, Mori H, Asada T, Takahashi R, Iwata N, Yamanaka S, Inoue H (2013) Modeling Alzheimer's disease with iPSCs reveals stress phenotypes associated with intracellular $\mathrm{A} \beta$ and differential drug responsiveness. Cell Stem Cell 12, 487-496.
[60] Ma QL, Teter B, Ubeda OJ, Morihara T, Dhoot D, Nyby MD, Tuck ML, Frautschy SA, Cole GM (2007) Omega-3 fatty acid docosahexaenoic acid increases SorLA/LR11, a sorting protein with reduced expression in sporadic Alzheimer's disease (AD): Relevance to AD prevention. J Neurosci 27, 14299-14307.

[61] Ota M, Matsuo J, Ikki I, Takano H, Al E (2019) Effects of a medium-chain triglyceride-based ketogenic formula on cognitive function in patients with mild-to-moderate Alzheimer's disease. Neurosci Lett 690, 232-236.

[62] Sachdev PS (2005) Homocysteine and brain atrophy. Prog Neuro-Psychopharmacology Biol Psychiatry 29, $1152-1161$.

[63] Smith AD, Smith SM, de Jager CA, Whitbread P, Johnston C, Agacinski G, Oulhaj A, Bradley KM, Jacoby R, Refsum H (2010) Homocysteine-lowering by b vitamins slows the rate of accelerated brain atrophy in mild cognitive impairment: A randomized controlled trial. PLoS One $\mathbf{5}, 1-10$.

[64] Craft S, Asthana S, Schellenberg G, Baker L, Cherrier M, Boyt AA, Martins RN, Raskind M, Peskind E, Plymate S (2000) Insulin effects on glucose metabolism, memory, and plasma amyloid precursor protein in Alzheimer's disease differ according to apolipoprotein-E genotype. Ann $N$ Y Acad Sci 903, 222-228.

[65] Yamini P, Ray RS, Chopra K (2018) Vitamin D 3 attenuates cognitive deficits and neuroinflammatory responses in ICV-STZ induced sporadic Alzheimer's disease. Inflammopharmacology 26, 39-55.

[66] Buell JS, Dawson-Hughes B (2008) Vitamin D and neurocognitive dysfunction: Preventing "D"ecline? Mol Aspects Med 29, 415-422.

[67] Salkovic-Petrisic M, Osmanovic-Barilar J, Brückner MK, Hoyer S, Arendt T, Riederer P (2011) Cerebral amyloid angiopathy in streptozotocin rat model of sporadic Alzheimer's disease: A long-term follow up study. J Neural Transm 118, 765-72

[68] Ravelli KG, Rosário BDA, Vasconcelos AR, Scavone C, Camarini R, Hernandes MS, Britto LR (2017) NADPH oxidase contributes to streptozotocin-induced neurodegeneration. Neuroscience 358, 227-237.

[69] Chen Y, Liang Z, Blanchard J, Dai CL, Sun S, Lee MH, Grundke-Iqbal I, Iqbal K, Liu F, Gong CX (2012) A nontransgenic mouse model (icv-STZ Mouse) of Alzheimer's disease: Similarities to and differences from the transgenic model (3xTg-AD Mouse). Mol Neurobiol 47, 711-725. 